physicians developed symptoms of fever, chills, and myalgias after treatment with nelfinavir. The possibility of acute hepatitis $\mathrm{C}$ was considered, because, in both of these cases, the healthcare workers were exposed to $\mathrm{HCV}$ along with HIV. However, serology for acute $\mathrm{HCV}$ was negative in repeated qualitative testing for hepatitis C viremia by PCR. Additionally, other infectious hepatitis were in our differential diagnosis, including hepatitis $A$ and $G$, as well as cytomegalovirus (CMV) infection. The resident had a negative CMV titer when he developed jaundice. The clinical presentation, with only mild elevations of liver enzymes and rapid improvement following cessation of nelfinavir therapy, suggested most likely a drug-induced problem. Furthermore, there were increases in alkaline phosphatase, right upper quadrant pain, and hepatomegaly, suggesting a cholestatic process in both physicians. ${ }^{5}$ The symptoms promptly subsided with cessation of all medica- tions and continued to improve when the physicians were rechallenged with only zidovudine and lamivudine. The possibility of nelfinavir-induced hepatotoxicity was suspected because of earlier reports of liver toxicity associated with other protease inhibitors. Although there is one case report of acute pancreatitis with nelfinavir therapy, in our two cases, amylases were within normal range. The two patients were monitored closely and agreed to continue with zidovudine and lamivudine after cessation of the three-drug regimen and clinical improvement of symptoms. Diarrhea and nausea also resolved with the discontinuation of nelfinavir. Vomiting and slight dehydration improved rapidly in one patient when he stopped taking nelfinavir.

In summary, our data suggests that nelfinavir may provoke cholestatic hepatotoxicity after the second week of therapy. Although other protease inhibitors have been reported to cause liver toxicity, this is the first report of possible toxic hepatitis from nelfinavir therapy.

\section{REFERENCES}

1. Centers for Disease Control and Prevention. CDC Public Health Service guidelines for the management of health care workers exposures to HIV and recommendations for postexposure prophylaxis. MMWR 1998;47(RR7):1-33.

2. Cardo DM, Bell DM. Bloodborne pathogen transmission in health care workers. Infect Dis Clin North Am 1997;11:331-346.

3. Beach JW. Chemotherapeutic agents for HIV infection: mechanism of action, pharmacokinetics, metabolism and adverse reactions. Clin Ther 1998;20:2-25.

4. Pai V, Nahata M. Nelfinavir mesylate: a protease inhibitor. Ann Pharmacother 1999; 33:325-339.

5. Lewis JH, Zimmerman HJ. Drug and chemical-induced cholestasis. Clin Liver Dis 1999;3:433-464.

Marcia Trapé, MD Sandra Barnosky, APN University of Connecticut School of Medicine Farmington, Connecticut

\title{
Eradication of MRSA From a Health Center Ward and Nursing Home
}

\author{
Gina Pugliese, RN, MS \\ Martin S. Favero, PhD
}

Long-term healthcare facilities have been recognized as reservoirs of multiresistant bacterial strains, especially methicillin-resistant Staphylococcus aureus (MRSA). Efforts to control MRSA in this setting usually have been only partially effective. Kotilainen and colleagues from Turku University Central Hospital, Turku, Finland, in a recent article describe the eradication of epidemic MRSA from a Finnish healthcare center ward and affiliated nursing home.

The methods to control MRSA included (1) contact isolation precautions, (2) screening for asymptomatic carriage, (3) eradication of carriage, and (4) education of staff on hygienic measures. The first six patients with MRSApositive findings were referred without delay to the infectious diseases unit of the adjacent university hospital for eradication treatment. Later, an isolation unit of six rooms was founded in the healthcare center, where the MRSA-colonized patients were nursed as a separate cohort until they, in succession, were referred to the infectious diseases unit for decolonization.

From May 20 through August 17, 1993, the epidemic MRSA strain was isolated from 8 long-term patients on the $40-$ bed ward of the healthcare center, 4 of the 59 residents of the nursing home, and 1 member of the staff. Eradication of car- riage was successful in all except 1 patient with dementia, who was nursed in contact isolation in the healthcare center until his death 21 months later.

The authors concluded that it is possible to eradicate MRSA from a long-term healthcare facility, even after 13 cases, by applying strict control measures. Their experience may be valuable in the future decision-making process for control of new and more challenging multiresistant bacteria.

FROM: Kotilainen P, Routamaa M, Peltonen R, Evesti P, Eerola E, Salmenlinna $\mathrm{S}$, et al. Eradication of methicillin-resistant Staphylococcus aureus from a health center ward and associated nursing home. Arch Intern Med 2001;26;161:859-863. 